\title{
Solid Glomus Tumor
}

National Cancer Institute

\section{Source}

National Cancer Institute. Solid Glomus Tumor. NCI Thesaurus. Code C51133.

The most common morphologic variant of glomus tumor. It is characterized by the presence of a nest of glomus cells surrounding capillary sized vessels. 